\title{
COMPARAÇÃO ENTRE ARGAMASSA CONVENCIONAL E ARGAMASSA COM
}

ADITIVO IMPERMEABILIZANTE

Mirian Alves $^{1}$
Natália Cristina Bleichvel $^{2}$

\section{RESUMO}

Este artigo trata a respeito da argamassa, um dos componentes mais utilizados na construção civil, pois sem ela não seria possível ver as construções que temos nos dias de hoje. Sendo assim, entendemos que a argamassa é muito importante em qualquer construção feita com pedras, tijolos ou blocos cerâmicos, já que tem a função de unir esses materiais entre si. Dessa forma, pode-se dizer que a argamassa tem grande parcela de colaboração na durabilidade das edificações. Levando-se em consideração a importância da argamassa numa edificação, é necessário avaliar os parâmetros de resistência a compressão para que a edificação não tenha sua vida útil prejudicada. Em razão disso existem no mercado vários produtos de ação impermeabilizante, adesiva ou plastificante, que podem ser utilizados como aditivos para o preparo de argamassas, já que sua principal função é a plasticidade da argamassa. Portanto, esse trabalho tem como objetivo comparar a resistência a compressão entre a argamassa tradicional, confeccionada com cimento e areia e a argamassa com aditivo impermeabilizante. O presente trabalho foi realizado no Laboratório de Materiais e Solos da Universidade Alto Vale do Rio do Peixe, em Caçador - SC. Primeiramente foi realizado a caracterização dos materiais, através dos ensaios de granulometria, massa específica e massa unitária. Em seguida será realizado o estudo de dosagem da argamassa, onde será confeccionada a argamassa sem aditivo e a argamassa com adição do aditivo impermeabilizante, sendo 2, 3 e 4\% de adição. Logo, foram realizados nas argamassas ensaios no estado fresco, como: massa específica e flowtable; já no estado endurecido foram

\footnotetext{
1 Acadêmica do curso de Engenharia Civil da UNIARP Campus Caçador. E-mail: mirian_a128@yahoo.com.br.

2 Professora Orientadora do curso de Engenharia Civil da UNIARP Campus Caçador. Engenheira Civil. E-mail: natalia.cristina@uniarp.edu.br.
} 
realizados os ensaios de resistência à compressão. $E$, por fim, foi realizado o comparativo em relação a resistência a compressão da argamassa.

Palavras-Chave: Argamassa. Impermeabilizante. Construção Civil.

\section{ABSTRACT}

This article is about mortar, one of the most used components in construction, because it is not possible see the constructions as we have today. We can say that mortar is very important in any construction made with stones, bricks or ceramic blocks, as has the function of joining these materials each other. Thus, we can say the a good mortar have a big portion of collaboration on durability of buildings. Considering the importance of mortar in a building, it is necessary to evaluate the compressive strength parameters so that the building does not have its useful life impaired. Due to this, there are several waterproofing, adhesive or plasticizing products on the market that can be used as additives for the preparation of mortars, since their main function is the production of mortars with great resistance to water penetration. As a result, this work has as objective to compare the compressive strength the mortar made with cement and sand and the mortar with waterproofing additive. This work was be carried out at the Laboratório de Materiais e Solos of the Universidade Alto Vale do Rio do Peixe, in Caçador - SC. Firstlyit will be accomplished the characterization of the materials, through the granulometry, specific mass and unit mass tests. Next, a mortar dosage study will be carried out, where the mortar without additive and the mortar with addition of the waterproofing additive will be made, being 2, 3 and $4 \%$ addition. Therefore, in the mortars, tests in the fresh state, such as: specific mass and flow table; already in the hardened state was be carried out the tests of resistance to compression of mortar.

Keywords: Mortar. Waterproofing. Construction.

\section{INTRODUÇÃO}

A argamassa é parte fundamental em uma obra de construção civil, já que sem ela não seria possível ver as construções que temos nos dias de hoje. Há vários meios em que utilizamos a argamassa, já que podemos ligar dois meios construtivos (como no assentamento de tijolos) e, pode servir também, como impermeabilizante, nivelador e regularizador de superfícies (como no caso do reboco, emboço e contrapiso) (CIVILIZAÇÃO ENGENHARIA, 2019; BLOG PRA 
CONSTRUIR, 2019).

Para sua fabricação devemos analisar para qual objetivo se deseja chegar. No assentamento de tijolos e blocos é realizado uma massa com cimento, cal ou aditivo, areia e água. Para o revestimento da alvenaria (ou reboco) é utilizado cimento, cal ou aditivo, areia e água. E como regularizadora (contrapiso) utilizamos cimento, areia e água. Lembrando que é importante fazer uma mistura homogênea com todos os materiais (CIVILIZAÇÃO ENGENHARIA, 2019; BLOG PRA CONSTRUIR, 2019).

Em razão disso podemos dizer que a argamassa é muito importante em qualquer construção feita com pedras, tijolos ou blocos cerâmicos, já que tem a função de unir esses materiais entre si. Podemos mencionar também a sua função como revestimento, pois proporciona uma maior proteção aos vários elementos construtivos. Dessa forma, podemos dizer que uma boa argamassa tem grande parcela de colaboração na durabilidade das edificações (SANTIAGO, 2007).

A utilização de aditivos na argamassa se faz necessária no dia a dia da obra. E, devido a importância da argamassa na construção civil, se faz o questionamento: em relação aos parâmetros de resistência à compressão da argamassa, comparando-se a argamassa de cimento e areia e a argamassa de cimento e areia com aditivo impermeabilizante, qual apresentará o melhor resistência e consequentemente o melhor desempenho na obra?

Existem no mercado atualmente uma infinidade de marcas e tipos de aditivos para argamassas, o aditivo que será estudado neste trabalho será o aditivo impermeabilizante, logo, se faz necessário o estudo da argamassa com a adição deste aditivo em comparação a argamassa sem a sua adição para compararmos o seu efeito em relação a resistência da argamassa.

O objetivo geral desse trabalho é comparar a resistência entre a argamassa confeccionada com cimento e areia e a argamassa com aditivo impermeabilizante. Dessa forma, os objetivos específicos são:
a) Caracterizar os materiais;
b) Realizar estudo de dosagem;
c) Realizar ensaios no estado fresco; 
d) Realizar ensaios no estado endurecido.

O presente trabalho foi realizado no Laboratório de Materiais e Solos da Universidade Alto Vale do Rio do Peixe - UNIARP, em Caçador - SC. Primeiramente foi realizado a caracterização dos materiais, através dos ensaios de granulometria, massa específica e absorção de água e massa unitária. Em seguida foi realizado o estudo de dosagem da argamassa, onde será confeccionada a argamassa sem aditivo e a argamassa com adição do aditivo impermeabilizante, sendo 2, 3 e 4\% de adição. E, foram realizados nas argamassas ensaios no estado fresco, que são: índice de consistência e densidade de massa. Já no estado endurecido foi realizado o ensaio de resistência à compressão.

\section{METODOLOGIA E MATERIAL}

A metodologia para a realização deste trabalho se dá a partir de ensaios laboratoriais para a caracterização do agregado miúdo, granulometria, massa unitária, massa específica e absorção de água, dosagem da argamassa, moldagem dos corpos de prova de argamassa, determinação das propriedades da argamassa no estado fresco tais como Índice de consistência e densidade de massa. Bem como a determinação das propriedades da argamassa no estado endurecido através da realização do ensaio de Resistência à compressão.

\section{CARACTERIZAÇÃO DO AGREGADO MIÚDO}

Os ensaios de caracterização dos agregados miúdos foram realizados no Laboratório de Materiais de Construção da Universidade Alto Vale do Rio do Peixe - UNIARP na cidade de Caçador de acordo com as normas vigentes.

\section{Ensaio de granulometria}

Para determinar o ensaio de granulometria foram utilizadas as recomendações da NBR NM 248 (ABNT, 2003) - Agregados - Determinação da composição granulométrica.

Primeiramente, foi preciso secar as amostras em estufa por 24 horas. Após 
retirado da estufa, foi deixado esfriar a temperatura ambiente e determinado as massas ( $\mathrm{m} 1 \mathrm{e} \mathrm{m} 2$ ).

Em seguida foi encaixado as peneiras, de modo a formar um conjunto de peneiras, em ordem crescente da base até o topo. As peneiras utilizadas foram: 9,5 $-4,75-2,06-1,18-0,60-0,30-0,15 \mathrm{~mm}$ e o fundo. A amostra foi colocada na peneira superior do conjunto e iniciado a agitação no agitador de peneiras.

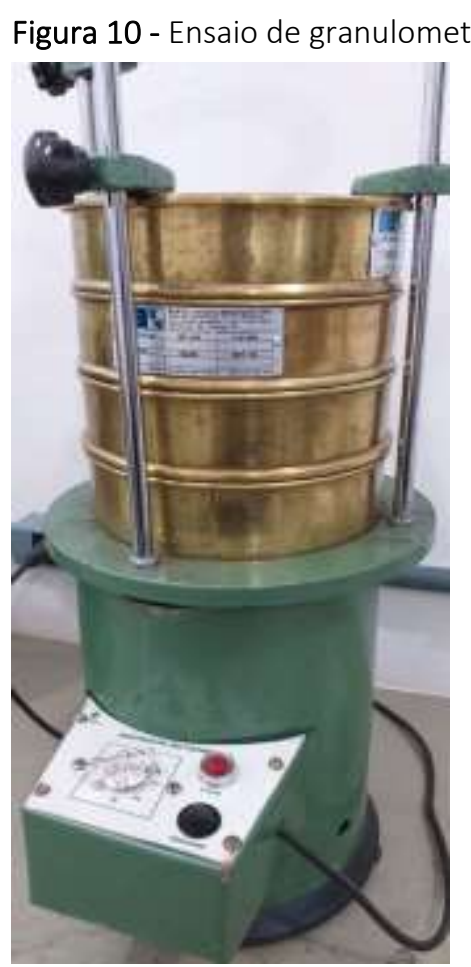

Fonte: O próprio autor (2019)

Após a remoção do material retido na peneira para uma determinada bandeja. Foi escovado a tela para que não ficasse nenhum resíduo. Sendo que, o material removido pelo lado interno foi considerado como retido e o desprendido como passante.

Prosseguido com o método acima até que todas as peneiras tivessem sido verificadas. Por último foi determinado a massa total de material retido em cada uma das peneiras e no fundo do conjunto. 


\section{Massa unitária}

Para determinar a massa unitária foram utilizadas as recomendações da NBR NM 45 (ABNT, 2006)- Agregados - Determinação da massa unitária e do volume de vazios.

Segundo a NBR NM 45 (ABNT, 2006, p. 1), massa unitária é a "relação entre a massa do agregado lançado no recipiente de acordo com o estabelecido nesta Norma e o volume desse recipiente".

Para a realização dos ensaios da NBR NM 45 (ABNT, 2006), foram necessários os seguintes aparelhos e instrumentos: balança, haste de adensamento, recipiente, pá ou concha, placa de calibração e estufa.

A amostra foi constituída com aproximadamente $150 \%$ da quantidade de material requerido para encher o recipiente e foi manipulada cuidadosamente a fim de evitar sua segregação. Após isso, foi realizado a secagem em estufa (NBR NM 45, ABNT, 2006).

Para a realização do ensaio, pôde-se optar pela realização de três métodos distintos. O método $A$ deve ser escolhido quando os agregados têm dimensão máxima de 37,5 mm ou menor. No método $B$, quando os agregados têm dimensão máxima superior a $37,5 \mathrm{~mm}$ e inferior a $75 \mathrm{~mm}$. E, o método $C$ quando o material estiver no estado solto. O método utilizado para os ensaios foi o método C (NBR NM 45, ABNT, 2006).

Para a realização do ensaio o agregado miúdo foi mantido em estufa a temperatura de $\pm 105^{\circ} \mathrm{C}$ por 24 horas.

Primeiramente foi determinado a massa do recipiente em kg, então foi enchido com areia até transbordar e nivelado a camada superior com uma régua metálica e pesado. Por último, o recipiente foi enchido com água para se obter o seu volume e pesado.

\section{Massa específica e absorção de água}

Para a determinação da massa específica e massa específica aparente, seguiu-se os procedimentos conforme a NBR NM 52 (ABNT, 2003) que descreve o método de determinação da massa específica e da massa específica aparente dos 
agregados miúdos.

Para a realização desse ensaio foi necessário: balança, frasco aferido, molde tronco-cônico, haste de compactação, estufa, bandeja metálica, espátula de aço, circulador de ar regulável e dessecador (NBR NM 52, ABNT, 2003).

Após deixado a amostra por 24 horas em estufa, foi separado $1 \mathrm{~kg}$ de areia e deixado de molho na água. Depois de $24 \mathrm{~h}$ na água, foi retirado e excesso de água e secado com uma leve brisa no mesmo recipiente.

Então, foi colocado no molde tronco cônico e socado 25 vezes com a haste de compactação. Para ter a certeza que o ensaio foi realizado com sucesso, a amostra desmoronou.

Então, foi realizado a pesagem de $500 \mathrm{~g}$ de amostra e colocado em um frasco aferido, registrando a massa de ambos. Após esse passo, o frasco foi enchido com água até $500 \mathrm{ml}$ e sacudido para eliminar as bolhas de ar, após colocá-lo em um banho mantido a temperatura constante entre 2 à $21^{\text {ㅇC. }}$.

Após 1 hora, foi completado com água até $500 \mathrm{~cm}^{3}$ e determinado a massa total com precisão de $0,1 \mathrm{~g}(\mathrm{~m} 2)$.

Figura 11 - Picnômetro com água

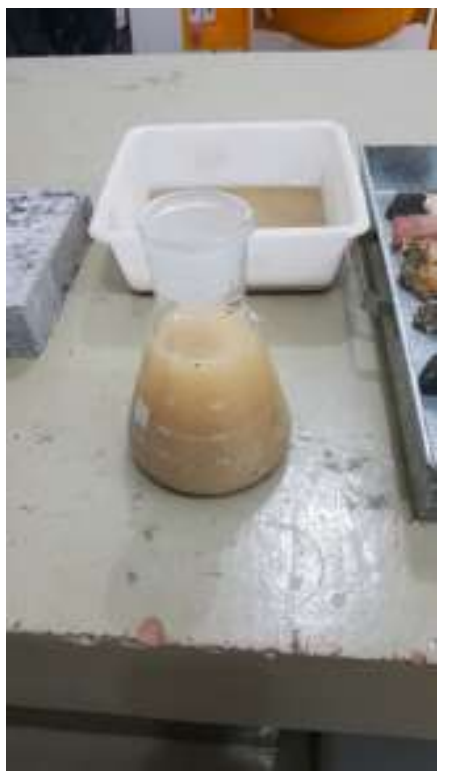

Fonte: O próprio autor (2019) 
Por último, retirado o agregado miúdo do frasco e secado em estufa. Esfriado à temperatura ambiente em um recipiente e pesado com precisão de 0,1 g (NM 52, ABNT, 2003).

\section{ESTUDO DE DOSAGEM DA ARGAMASSA}

O produto que foi utilizado foi o Vedacit para a comparação entre a argamassa convencional e a argamassa com impermeabilizante.

O Vedacit é um produto vendido nas embalagens de $1 \mathrm{~L}(1,05 \mathrm{~kg}), 3,6 \mathrm{~L}$ (3,78 kg), 18 L (18,9 kg) e 200 L (210 kg) (VEDACIT, 2019).

Quanto as características do produto, tudo dependerá de sua aplicação. Nos baldrames, deve-se limpar a superfície e chapiscá-la com um adesivo de alto desempenho para argamassas e chapiscos. Deve-se aguardar com um mínimo de três dias para aplicação do revestimento. Esse revestimento deve ser feito no traço 1:3 (cimento:areia média peneirada) e usar junto com a água 2 litros de Vedacit para cada saco de cimento $50 \mathrm{~kg}$ utilizado (VEDACIT, 2019).

Dessa forma, os traços de impermeabilizante que serão utilizados nos ensaios será o traço 1:3 sem aditivo e com aditivo nas porcentagens de $2 \%$, $3 \%$ e $4 \%$ em relação a massa de cimento, totalizando quatro traços.

A quantidade de material usada no traço 1:3 foi:

02 kilogramas de cimento;

06 kilogramas de areia fina;

1,2 litros de água.

A quantidade de aditivo usada na porcentagem de $2 \%$ foi 0,04 kilogramas, na porcentagem de $3 \%$ foi 0,06 kilogramas e na porcentagem $4 \%$ foi 0,08 kilogramas.

MOLDAGEM DOS CORPOS DE PROVA DE ARGAMASSA

Para determinar a moldagem dos corpos de prova de argamassa foramutilizado os procedimentos conforme a NBR 7215 (ABNT, 1996) -Cimento 
Portland - Determinação da resistência à compressão.

Para a determinação da resistência à compressão foram utilizados corpos de prova cilíndricos de $50 \mathrm{~mm}$ de diâmetro e $100 \mathrm{~mm}$ de altura (NBR 7215, ABNT, 1996).

Antes de se iniciar a fabricação da argamassa foi aplicado óleo desmoldante nos corpos de prova (NBR 7215, ABNT, 1996).

Ao iniciar a argamassa, foi adicionado inicialmente ao misturador mecânico toda a quantidade de água, para então adicionar o cimento. A areia foi adicionada aos poucos, se incorporando à massa totalmente. Para que não fosse perdido nenhuma quantidade significativa de areia e cimento, o misturador mecânico foi desligado e o material foi desprendido das paredes, sendo ligado novamente para que toda a parcela de areia e cimento se aderisse a massa. Após todo esse processo, a massa foi utilizada nos corpos de prova (NBR 7215, ABNT, 1996).

Os corpos de prova foram preenchidos com argamassa logo após sua fabricação com a ajuda dos instrumentos necessários. Com o soquete foi colocado quatro camadas e aplicado 30 golpes em cada camada. Após o seu enchimento, a massa foi rasada com a utilização do próprio instrumento utilizado para encher os moldes (NBR 7215, ABNT, 1996).

Após moldados, os corpos de prova foram conservados em atmosfera para cura inicial, e após 24 horas desmoldados e submetidos à cura em água saturada de cal hidratada até a data de ruptura (NBR 7215, ABNT, 1996). 
Figura 12 - Corpos de prova no tanque

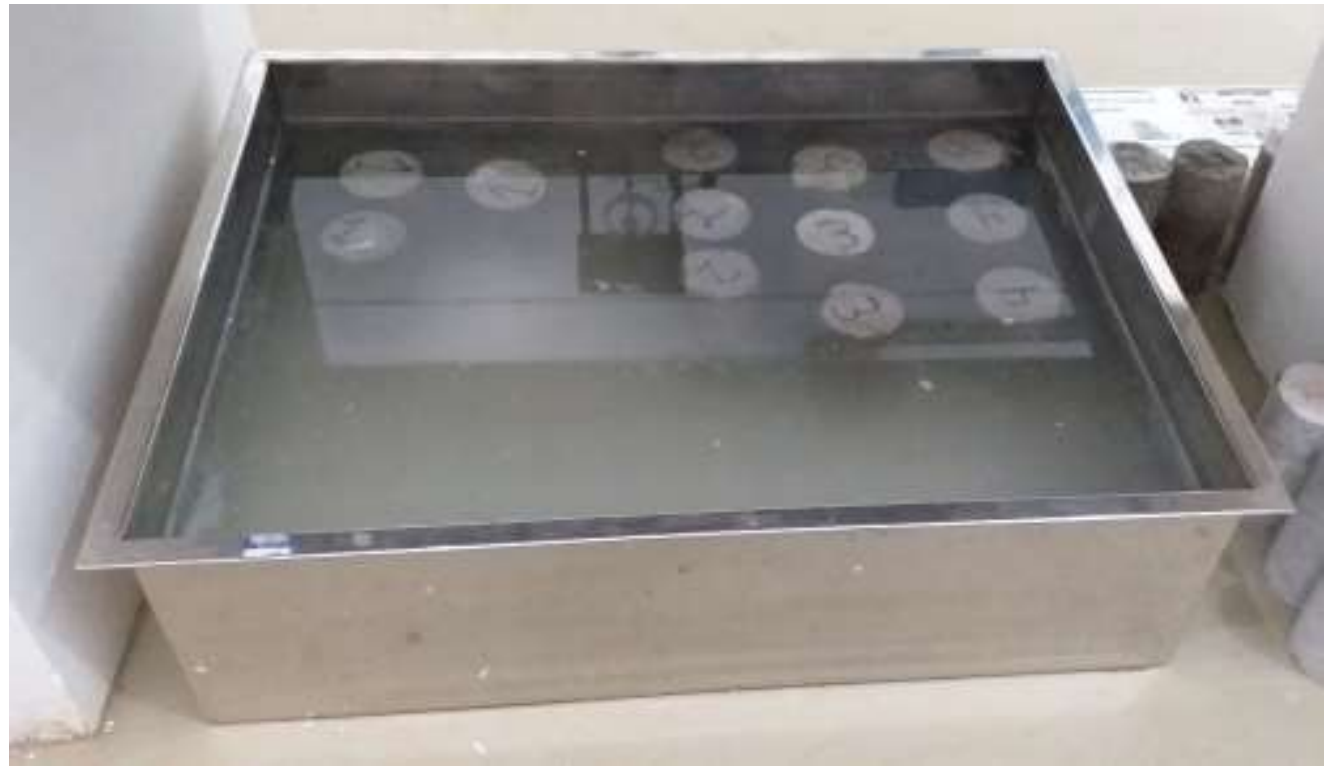

Fonte: O próprio autor (2019)

Como mostra a imagem acima, os corpos de prova foram mantidos no tanque com água e cal hidratada até o dia de ruptura. As rupturas nos corpos de prova foram realizadas na idade de 7, 14 e 28 dias.

PROPRIEDADES DA ARGAMASSA NO ESTADO FRESCO

\section{Índice de consistência}

Para a determinação do índice de consistência, seguiu-se os procedimentos conforme a NBR 13276 (ABNT, 2002) que descreve o método de determinação do índice de consistência das argamassas para assentamento e revestimento de paredes e tetos.

Para a realização do ensaio, foi limpado e secado o tampo da mesa para índice de consistência e a parede do molde com troncônico com um pano (NBR 13276, ABNT, 2002).

Após preparada a argamassa, utilizado uma quantidade para encher o molde troncônico. Segurado o molde sobre a mesa para índice de consistência e 
enchido três camadas de argamassa, com alturas aproximadamente iguais, e aplicado em cada uma delas quinze, dez e cinco golpes com o soquete (NBR 13276, ABNT, 2002).

Foi feito o rasamento da argamassa com régua metálica com movimentos curtos de vai e vem e eliminado qualquer partícula em volta do molde com pano seco e limpo (NBR 13276, ABNT, 2002).

Retirado o molde troncônico verticalmente, foi mexido com manivela da mesa, de modo que a mesa subia e caia 30 vezes em 30 segundos uniformemente. Como podemos ver na Figura 05, a FlowTabledo laboratório não tem acionamento elétrico, dessa forma foi efetuado o acionamento manualmente (NBR 13276, ABNT, 2002).

Logo após a última queda, foi medido com uma regra o espalhamento da argamassa. Estas medidas foram feitas em três diâmetros tomados em pares de pontos distribuídos ao longo do perímetro. Todas as medidas foram anotadas (NBR 13276, ABNT, 2002).

Figura 13 - FlowTable para argamassa

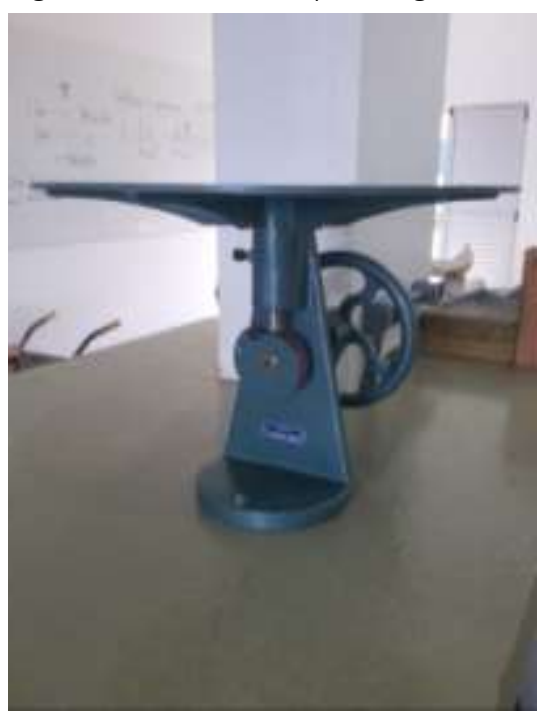

Fonte: O próprio autor (2019) 


\section{Densidade de massa}

Para a determinação da densidade de massa foram seguidos os parâmetros conforme a NBR 13278 - Argamassa para assentamento e revestimento de paredes e tetos - Determinação da densidade de massa e do teor de ar incorporado (NBR 13278, ABNT, 2005).

Para esse ensaio foram utilizados os seguintes aparelhos: balança, recipiente (rígido, de material não absorvente e cilíndrico), espátula, placa (de vidro plano e transparente) e utensílios gerais de laboratório (NBR 13278, ABNT, 2005).

Primeiro foi realizado a calibração do recipiente cilíndrico, onde pesou-se o recipiente vazio com a placa de vidro e anotado a massa $\left(m_{V}\right)$. Após, encheu-se o recipiente com água destilada e registrou-se o seu volume $\left(v_{r}\right)$. Por último, rasado o recipiente com a placa de vidro, para que não ficassem bolhas de ar, e pesado novamente anotando sua massa $\left(m_{a}\right)$. O cálculo do volume foi: $v_{r}=$ $m_{a}-m_{v}$ (NBR 13278, ABNT, 2005).

Após a argamassa ser preparada, foi colocado porções de argamassa no recipiente cilíndrico calibrado, formando três camadas de alturas aproximadamente iguais. Em cada uma das camadas foi aplicado vinte golpes. $\mathrm{Na}$ primeira camada, não foi batido contra o fundo do recipiente, e nas demais, foi usada somente a força necessária para penetrar na superfície da camada imediatamente inferior (NBR 13278, ABNT, 2005).

Terminado o procedimento anterior, foi efetuado três quedas do recipiente com altura de aproximadamente $3 \mathrm{~cm}$. Levando em conta que não ficou vazios entre a argamassa e a parede do recipiente (NBR 13278, ABNT, 2005).

Por último, rasado o recipiente com a espátula, pesado e registrado a massa do cilindro com a argamassa $\left(m_{c}\right)$ (NBR 13278, ABNT, 2005). 
Figura 14 - Recipiente cilíndrico com argamassa

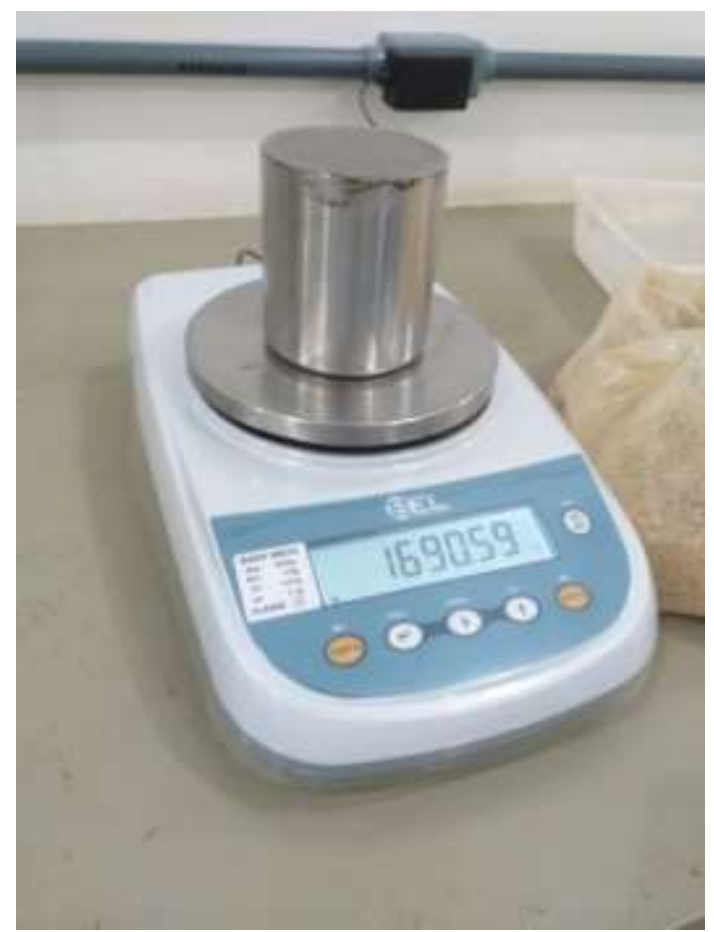

Fonte: O próprio autor (2019)

Para a obtenção da massa específica da $\operatorname{argamassa~(d),~no~estado~fresco~e~}$ em kg/m³, foi aplicado a seguinte equação (NBR 13278, ABNT, 2005):

$$
d=\frac{m_{c}-m_{v}}{v_{r}} 1000
$$

Onde:

$m_{c}$ : é a massa do recipiente cilíndrico contendo a argamassa do ensaio (g); $m_{v}$ : é a massa do recipiente cilíndrico vazio $(\mathrm{g})$; $v_{r}$ : é o volume do recipiente cilíndrico $\left(\mathrm{cm}^{3}\right)$. 
PROPRIEDADES DA ARGAMASSA NO ESTADO ENDURECIDO

Tal como as propriedades do concreto, que deve ser em seu estado endurecido resistente e ao mesmo tempo durável (Schwartz e Cassol, 2018), o mesmo deve-se verificar as propriedades para as argamassas em estado endurecido, como a resistência à compressão.

\section{Resistência à compressão}

Para a verificação da resistência à compressão das argamassas, posicionou-seo corpo de prova no dispositivo de apoio do equipamento de ensaio, de modo que a face rasada não ficasse em contato com os dispositivos de apoio nem com o dispositivo de carga. E foi aplicado carga entre 50 à $500 \mathrm{~N} / \mathrm{s}$ até a ruptura (NBR 13279, ABNT, 2005).

\section{ANÁLISE DOS DADOS E RESULTADOS}

Nesse tópico serão apresentados os resultados dos ensaios realizados ao longo do semestre no laboratório de Materiais de Construção Civil da UNIARP. A realização dos ensaios se deu seguindo suas respectivas normas técnicas.

CARACTERIZAÇÃO DOS MATERIAIS UTILIZADOS

\section{Agregado miúdo natural}

Ensaio de granulometria

Segundo a NBR 7211 (ABNT, 2005) o agregado utilizado foi considerado como areia fina. Abaixo apresentação dos resultados obtidos no laboratório. 
Tabela 01 - Análise granulométrica do agregado miúdo de areia natural

\begin{tabular}{|c|c|c|c|c|c|c|c|c|c|c|c|}
\hline \multirow[b]{2}{*}{$\begin{array}{l}\text { Peneira } \\
\mathrm{s}(\mathrm{mm})\end{array}$} & \multicolumn{4}{|c|}{$1^{\circ}$ Amostra } & \multicolumn{4}{|c|}{$2^{\circ}$ Amostra } & \multirow{2}{*}{\begin{tabular}{|l}
$\%$ \\
Retid \\
a \\
Médi \\
a
\end{tabular}} & \multirow[b]{2}{*}{$\begin{array}{l}\% \\
\text { Acumul } \\
\text { ada }\end{array}$} & \multirow{2}{*}{$\begin{array}{l}\% \\
\text { Passa } \\
\text { nte } \\
\text { médi } \\
\text { a }\end{array}$} \\
\hline & $\begin{array}{l}\text { Peso } \\
\text { retid } \\
\text { o (g) }\end{array}$ & $\begin{array}{l}\% \\
\text { Retid } \\
a\end{array}$ & $\begin{array}{l}\% \\
\text { Acumul } \\
\text { ada }\end{array}$ & $\begin{array}{l}\% \\
\text { Passa } \\
\text { nte }\end{array}$ & $\begin{array}{l}\text { Peso } \\
\text { retid } \\
\text { o (g) }\end{array}$ & $\begin{array}{l}\% \\
\text { Retid } \\
\text { a }\end{array}$ & $\begin{array}{l}\% \\
\text { Acumul } \\
\text { ada }\end{array}$ & $\begin{array}{l}\% \\
\text { Passa } \\
\text { nte }\end{array}$ & & & \\
\hline \multirow[t]{2}{*}{9,5} & 0 & 0 & $0 \%$ & $100 \%$ & 0 & $0 \%$ & $0 \%$ & $100 \%$ & $0 \%$ & $0 \%$ & $100 \%$ \\
\hline & 0 & $0 \%$ & $0 \%$ & $100 \%$ & 0,05 & $0,01 \%$ & $0,01 \%$ & $\begin{array}{l}99,99 \\
\%\end{array}$ & $\begin{array}{l}0,005 \\
\%\end{array}$ & $0,005 \%$ & $100 \%$ \\
\hline 4,75 & & 0,977 & & 99,02 & & & & 99,13 & 0,919 & & 99,07 \\
\hline 2 & 4,88 & $\%$ & 0,977\% & $3 \%$ & 4,3 & $0,86 \%$ & $0,87 \%$ & $\%$ & $\%$ & $0,924 \%$ & $7 \%$ \\
\hline 1,18 & 9,74 & $\begin{array}{l}1,95 \\
\%\end{array}$ & $2,927 \%$ & $\begin{array}{l}97,07 \\
3 \%\end{array}$ & 9,86 & $\begin{array}{l}1,972 \\
\%\end{array}$ & $2,842 \%$ & $\begin{array}{l}97,15 \\
8 \%\end{array}$ & $\begin{array}{l}1,961 \\
\%\end{array}$ & $2,885 \%$ & $\begin{array}{l}97,11 \\
6 \%\end{array}$ \\
\hline 0,6 & $\begin{array}{l}29,4 \\
1\end{array}$ & $\begin{array}{l}5,888 \\
\%\end{array}$ & $8,815 \%$ & $\begin{array}{l}91,18 \\
5 \%\end{array}$ & $\begin{array}{l}29,6 \\
5\end{array}$ & $\begin{array}{l}5,931 \\
\%\end{array}$ & $8,773 \%$ & $\begin{array}{l}91,22 \\
7 \%\end{array}$ & $\begin{array}{l}5,909 \\
\%\end{array}$ & $8,794 \%$ & $\begin{array}{l}91,20 \\
6 \%\end{array}$ \\
\hline 0,3 & $\begin{array}{l}116 \\
6\end{array}$ & $\begin{array}{l}23,34 \\
3 \%\end{array}$ & $\begin{array}{l}32,158 \\
\%\end{array}$ & $\begin{array}{l}67,84 \\
2 \%\end{array}$ & $\begin{array}{l}120 \\
19\end{array}$ & $\begin{array}{l}24,04 \\
1 \%\end{array}$ & $\begin{array}{l}32,814 \\
\%\end{array}$ & $\begin{array}{l}67,18 \\
6 \%\end{array}$ & $\begin{array}{l}23,69 \\
2 \%\end{array}$ & $\begin{array}{l}32,486 \\
\%\end{array}$ & $\begin{array}{l}67,51 \\
4 \%\end{array}$ \\
\hline 0,15 & $\begin{array}{l}235 \\
7\end{array}$ & $\begin{array}{l}47,18 \\
\%\end{array}$ & $\begin{array}{l}79,338 \\
\%\end{array}$ & $\begin{array}{l}20,66 \\
2 \%\end{array}$ & $\begin{array}{l}230 \\
44\end{array}$ & $\begin{array}{l}46,09 \\
4 \%\end{array}$ & $\begin{array}{l}78,907 \\
\%\end{array}$ & $\begin{array}{l}21,09 \\
3 \%\end{array}$ & $\begin{array}{l}46,63 \\
7 \%\end{array}$ & $\begin{array}{l}79,123 \\
\%\end{array}$ & $\begin{array}{l}20,87 \\
8 \%\end{array}$ \\
\hline Fundo & $\begin{array}{l}103 \\
2\end{array}$ & $\begin{array}{l}20,66 \\
2 \%\end{array}$ & $100 \%$ & $0 \%$ & $\begin{array}{l}105 \\
45\end{array}$ & $\begin{array}{l}21,09 \\
3 \%\end{array}$ & $100 \%$ & $0 \%$ & $\begin{array}{l}20,87 \\
7 \%\end{array}$ & $100 \%$ & $0 \%$ \\
\hline $\begin{array}{l}\text { Total } \\
\text { (g) }\end{array}$ & $\begin{array}{l}499, \\
5\end{array}$ & & & & $\begin{array}{l}499, \\
94\end{array}$ & & & & & & \\
\hline $\begin{array}{l}\text { Módulo c } \\
\text { finura }\end{array}$ & & $\begin{array}{l}1,242 \\
16\end{array}$ & & & $\begin{array}{l}\text { Diâme } \\
\text { máxin }\end{array}$ & & 1,18 & & & & \\
\hline
\end{tabular}

Fonte: O próprio autor (2019)

Para a realização dos ensaios foram utilizadas duas amostras com $500 \mathrm{~g}$ cada. As amostras foram secas em estufa por um período de 24 horas e resfriada de forma natural para a realização dos ensaios. 
Gráfico 01 - Curva Granulométrica da areia

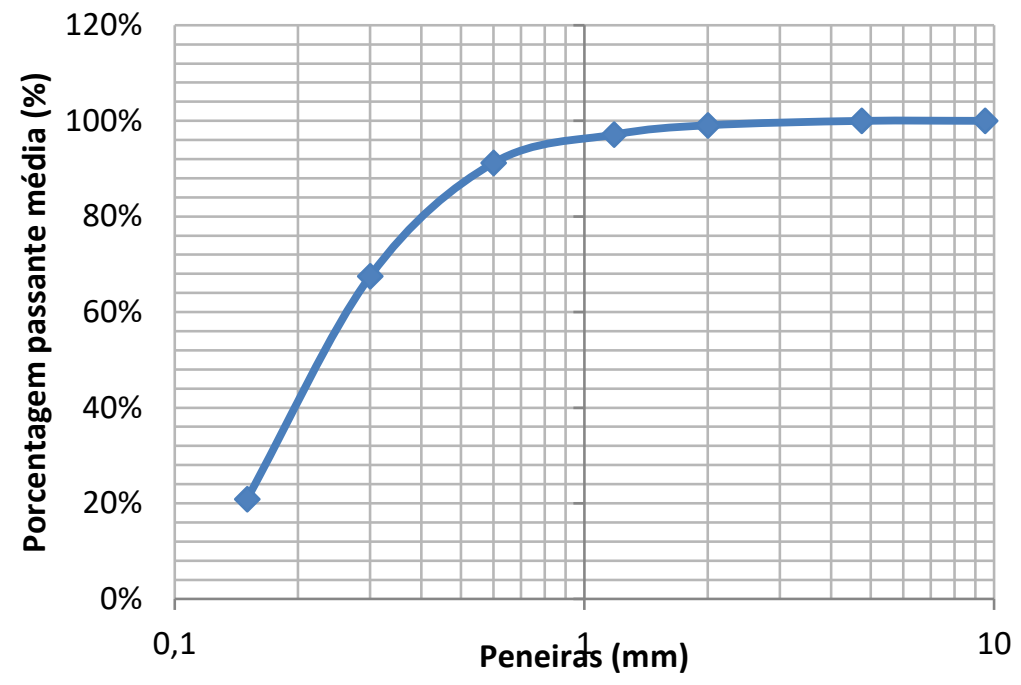

Fonte: O próprio autor (2019)

\section{Massa unitária}

Para a determinação da massa unitária foi seguido o método C da NBR NM 45 (ABNT, 2006). Para a realização desse ensaio foi determinada a massa do recipiente vazio em quilos. Após anotado sua massa, o recipiente foi preenchido com o agregado miúdo (areia) até que transbordasse, de forma que a camada superior de agregado miúdo fosse nivelada, para que então fosse anotado sua nova massa.

Tabela 2 - Massa unitária

\begin{tabular}{ll}
\hline Descrição & Valor \\
\hline Massa do recipiente $(\mathrm{kg})$ & 0,18 \\
Massa do recipiente $(\mathrm{kg})+$ Agregado miúdo $(\mathrm{kg})$ & 4,63 \\
Volume $\left(\mathrm{m}^{3}\right)$ & 0,00305 \\
Massa unitária $\left(\mathrm{kg} / \mathrm{dm}^{3}\right)$ & 1,46 \\
\hline
\end{tabular}

Fonte: O próprio autor (2019) 
Massa específica e absorção de água

Para a determinação da massa específica e massa específica aparente, seguiu-se os procedimentos conforme a NBR NM 52 (ABNT, 2003), ilustrados na Tabela 03:

Tabela 03: Massa específica e absorção de água

\begin{tabular}{lc}
\hline Massa da amostra $(\mathrm{g})$ & 500 \\
Volume do frasco $\left(\mathrm{cm}^{3}\right)$ & 500 \\
Peso seco da amostra $(\mathrm{g})$ & 494 \\
Massa específica $\left(\mathrm{g} / \mathrm{cm}^{3}\right)$ & 2,53 \\
Absorção de água (\%) & 1,21 \\
\hline
\end{tabular}

Fonte: O próprio autor (2019)

Propriedades da argamassa no estado fresco

Índice de consistência

Para a determinação do índice de consistência, seguiu-se os procedimentos conforme a NBR 13276 (ABNT, 2002) que descreve o método de determinação do índice de consistência das argamassas para assentamento e revestimento de paredes e tetos. Os resultados em centímetros estão expostos no Gráfico 02 abaixo.

Nesse ensaio uma porção de argamassa fresca foi colocada no molde tronco-cônico e após encher três camadas dando 5, 10 e 15 golpes com o soquete, mediu-se as extremidades da argamassa fresca. 0 gráfico 01 mostra os resultados do ensaio. 
Gráfico 02: Índice de Consistência

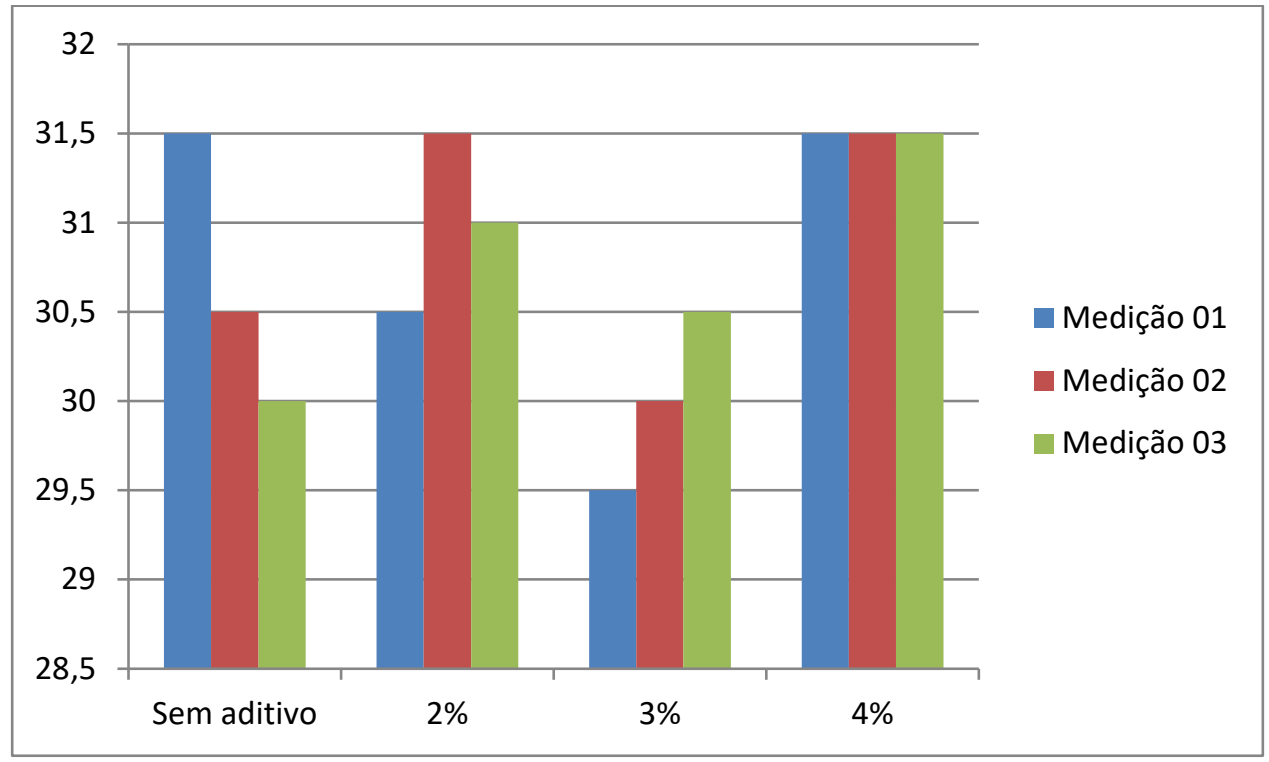

Fonte: O próprio autor (2019)

No gráfico acima podemos perceber que a argamassa com uma adição maior de aditivo impermeabilizante (4\%) possui um maior índice de consistência.

O índice de consistência está ligado diretamente a trabalhabilidade da argamassa. Dessa forma, os índices não devem ser muito elevados já que a argamassa estará muito mole e será difícil de aplicar, e nem muito baixos pois a argamassa não se espalhara na parede (COSTA, 2016).

Na realização do ensaio é possível perceber a diferença entre a argamassa com a maior porcentagem de aditivo (4\%) e a argamassa confeccionada sem aditivo. O aditivo dá uma maior plasticidade à argamassa. Abaixo imagens comparando a diferença entre ambas: 
Figura 15 - Argamassa com 4\% de aditivo

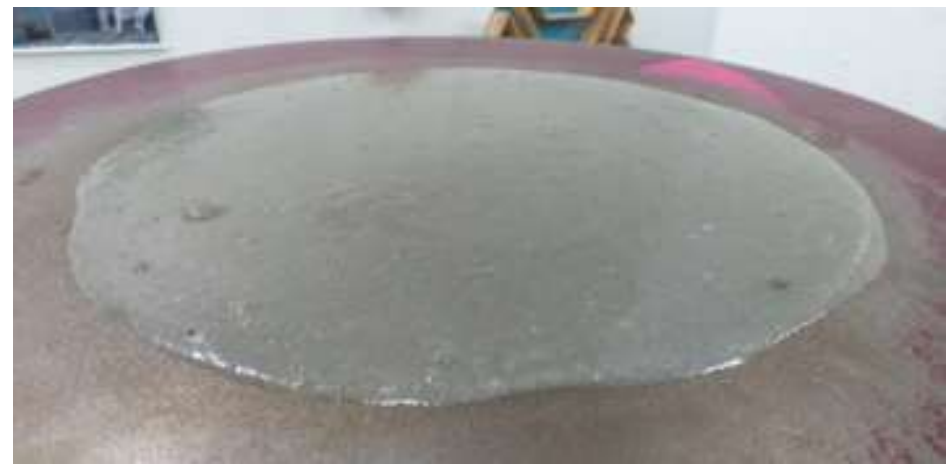

Fonte: O próprio autor (2019)

Na imagem acima a argamassa tem 4\% de aditivo e apresenta uma maior fluidez e é mais plástica.

Figura 16 - Argamassa sem aditivo

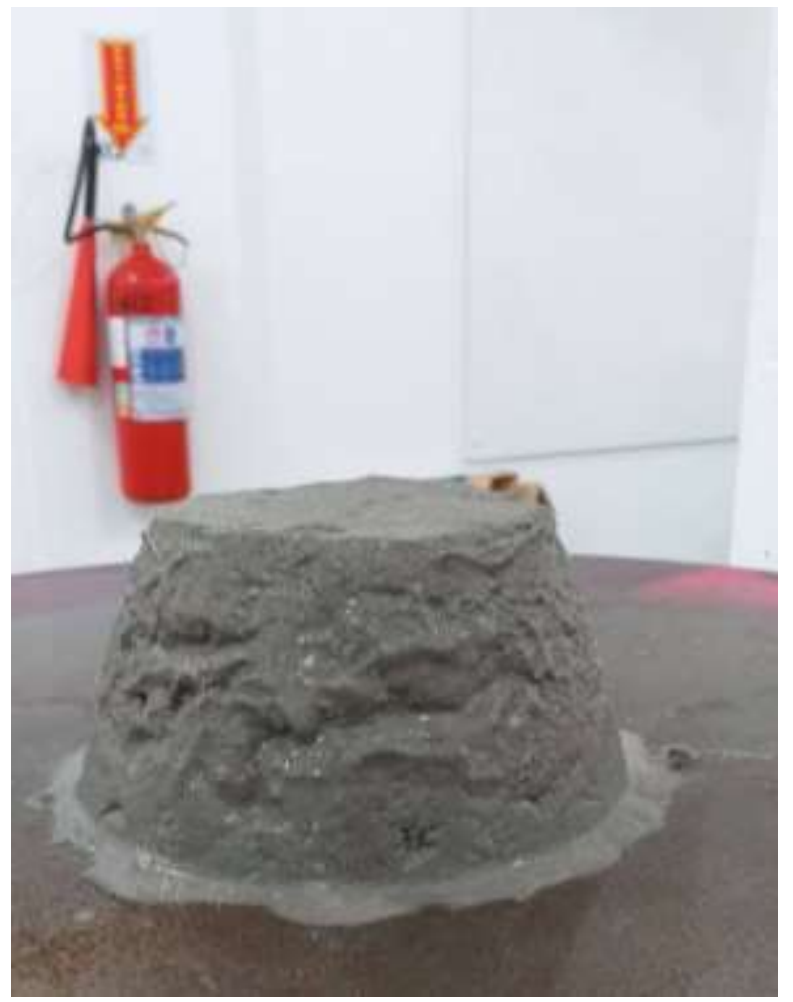

Fonte: O próprio autor (2019)

Na imagem acima a argamassa não tem nenhuma adição de aditivo e está 
menos plástica do que a argamassa com $4 \%$ de aditivo.

Dessa forma, as imagens acima mostram que mesmo utilizando a mesma quantidade de água em todos os traços, o aditivo irá aumentar a trabalhabilidade da massa.

Densidade de massa

Para a determinação da densidade de massa foram seguidos os parâmetros conforme a NBR 13278 - Argamassa para assentamento e revestimento de paredes e tetos - Determinação da densidade de massa e do teor de ar incorporado (NBR 13278, ABNT, 2005).

Gráfico 03 - Densidade de massa

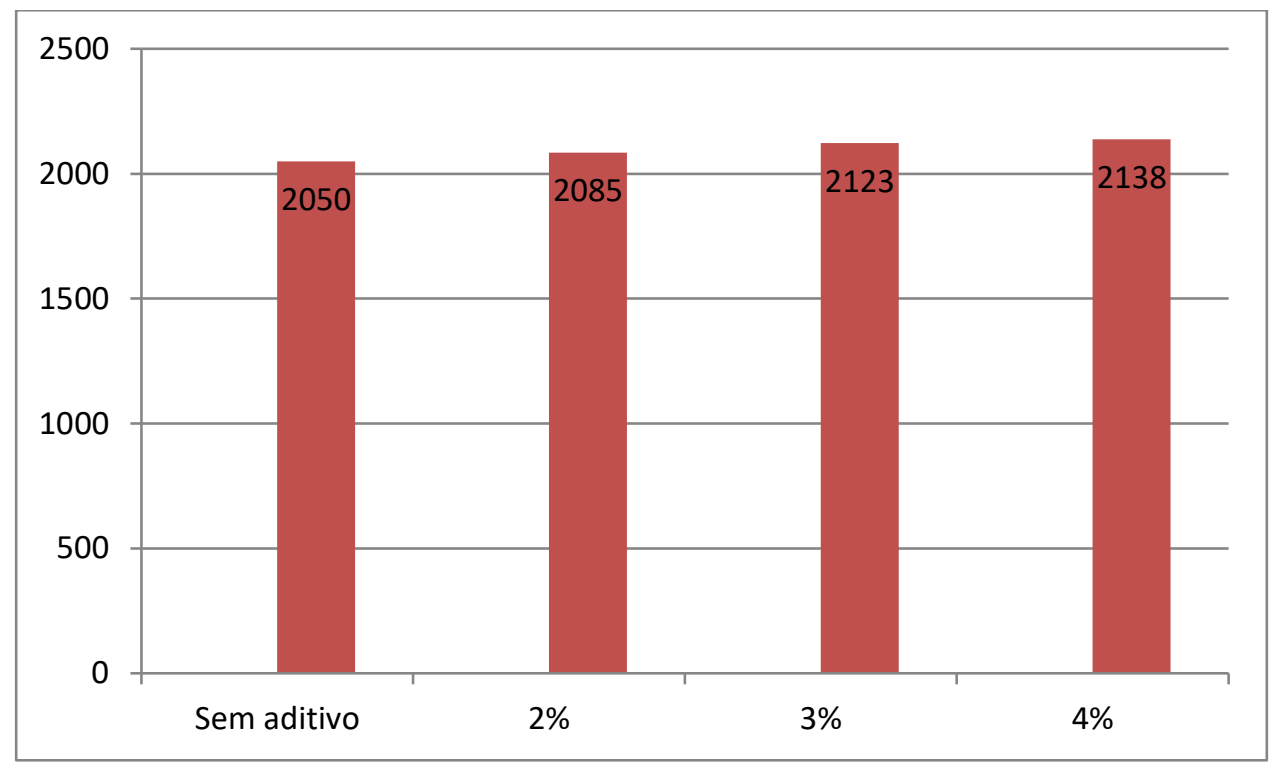

Fonte: O próprio autor (2019)

Acima apresenta-se o resultado do ensaio em $\mathrm{kg} / \mathrm{m}^{3}$. Esse resultado se encaixa na Classe D3 da NBR 13281 (ABNT, 2005), já que apresenta densidade $\geq$ $2000 \mathrm{Kg} / \mathrm{m}^{3}$.

A imagem acima mostra que as densidades da argamassa foram aumentando conforme o a porcentagem de aditivo iria aumentando, isso ocorreu porque o volume da argamassa aumentou. Isso explica a melhora da 
trabalhabilidade da argamassa com aditivo e seu rendimento. Esse fator é importante no dia a dia da obra já que reduz seu tempo e melhora a maleabilidade da massa.

Propriedades da argamassa no estado endurecido

Resistência à compressão

Para esse ensaio seguiu-se a NBR 7215 (ABNT, 1996), que determina a resistência à compressão de corpos de prova de argamassa. Os corpos de prova foram rompidos nas idades de 7, 14 e 28 dias. Abaixo o Gráfico 04 mostra os resultados em Mega Pascoal (Mpa):

Gráfico 04 - Resistência à compressão

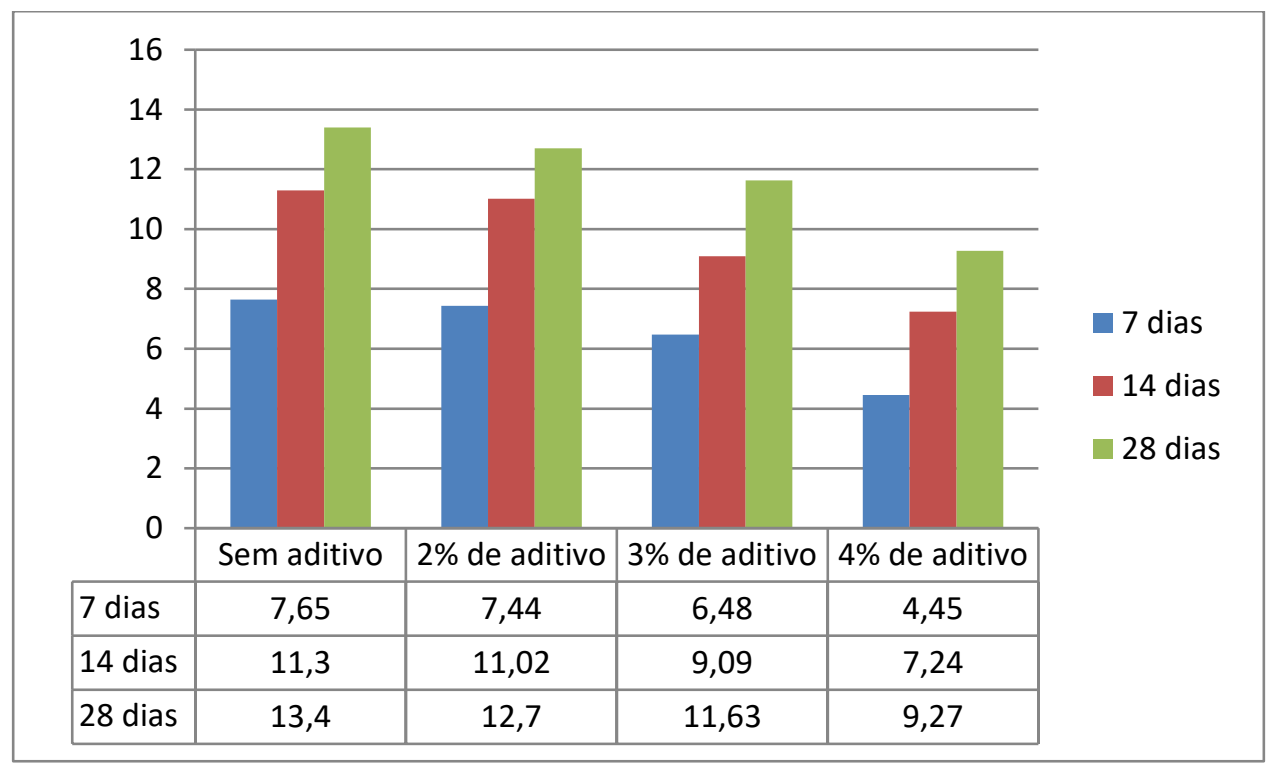

Fonte: O próprio autor (2019)

Como é possível perceber, a argamassa sem aditivo obteve resultados de resistência à compressão consideravelmente mais altos do que a argamassa com aditivo. Pode-se perceber também que quanto maior a adição de aditivo, menor será a resistência à compressão.

Aos 14 dias temos um significativo aumento de resistência em todos os 
corpos de prova, no corpo de prova com argamassa sem aditivos a porcentagem aos 14 dias aumentou 47,71\% em relação ao resultado de 7 dias. Até na porcentagem de $4 \%$ de aditivo percebemos um aumento de $62,7 \%$ dos 7 aos 14 dias.

\section{CONCLUSÃO}

Em decorrência da argamassa ser o material obtido através da mistura de uma pasta com um agregado miúdo, podendo ter aditivos ou não, podemos dizer que nas construções atuais é o modo de se unir os elementos construtivos e formar algo concreto (como uma parede, por exemplo).

Construções sem a utilização de aditivos tendem a não terem a mesma plasticidade e não serem maleáveis no dia a dia da obra, já que os aditivos são necessários para que na obra seja feita uma boa argamassa.

Dessa forma, esse trabalho teve como objetivo realizar estudos em laboratório, onde os ensaios foram feitos com as porcentagens de argamassa impermeabilizada. Também foi produzida a argamassa convencional, para que se fizesse a conferência de ambas.

O comparativo foi realizado em relação a resistência à compressão da argamassa, onde foi comparado a argamassa comum e a argamassa impermeabilizada com Vedacit nas seguintes proporções: 2, 3 e 4\%.

Primeiramente foi realizado a caracterização dos materiais, e o único material que foi caracterizado foi a areia, já que o cimento Portland e o aditivo já vêm com a caracterização de fábrica.

O segundo passo foi o estudo de dosagem dos materiais, onde a argamassa foi produzida com adição de aditivo, sendo 2, 3 e 4\% em relação a massa de cimento, e a argamassa sem aditivo.

Na realização dos ensaios no estado fresco, a argamassa apresentou maior trabalhabilidade em decorrência do aumento do volume. Isso foi demonstrado no resultado dos ensaios, que quanto maior a porcentagem de aditivo, mais plástica era a argamassa. Notório também foi a capacidade da argamassa render mais, tudo por causa do aumento do seu volume com a adição de aditivo impermeabilizante 
na mistura.

Com a argamassa fresca foram realizados os ensaios de índice de consistência e a densidade de massa. No ensaio do índice de consistência foi utilizado o flow table. E, a densidade de massa, onde foi obtido o volume e calculado a densidade da argamassa.

No ensaio de índice de consistência a argamassa sem aditivo impermeabilizante apresentou redução da sua consistência no decorrer das medições, a argamassa com $2 \%$ de aditivo impermeabilizante apresentou uma queda brusca na sua última medição e as dosagens com 3 e 4\% apresentaram evolução na sua consistência no decorrer das medições. A densidade de massa, que foi obtido o volume e calculado a densidade da argamassa, onde foi possível a verificação do aumento gradativo, conforme o aumento do percentual de aditivo na mistura.

Para a argamassa no estado endurecido foi verificada a resistência da argamassa na resistência à compressão.

A resistência à compressão está diretamente ligada ao fator água/aditivo, já que quanto maior a porcentagem de aditivo, menor será a resistência. Isso em todas as idades, dos 07 aos 14 e 28 dias. Embora todas as amostras tenham evoluído em sua resistência, conforme o tempo de cura, a resistência inicial das amostras com aditivo impermeabilizantes foram inferiores a resistência da amostra sem aditivo.

Dessa forma, de acordo com os resultados obtidos nessa pesquisa, verifica-se que o uso de aditivos influenciará negativamente na resistência à compressão da argamassa, mas irá ajudar na trabalhabilidade da argamassa no estado fresco. Por isso, na hora da execução da obra deve-se analisar qual parâmetro é mais importante, se utilizar uma argamassa com uma maior trabalhabilidade e ter uma redução da resistência à compressão; ou utilizar uma argamassa com uma resistência maior, mas menos plástica e mais difícil de trabalhar no dia a dia da obra.

Neste estudo constatou-se que o processo realizado para a análise da resistência da argamassa com adição de aditivos impermeabilizantes não alteraram as suas propriedades no estado fresco de forma a diminuir as suas propriedades e 
desempenho no estado fresco, apenas beneficiaram a argamassa através da trabalhabilidade. Porém, a argamassa com aditivos impermeabilizantes apresentaram resistência à compressão inferiores da argamassa convencional e houve uma redução significativa com o aumento da dosagem do aditivo impermeabilizante.

\section{REFERÊNCIAS}

ASSOCIAÇÃO BRASILEIRA DE NORMAS TÉCNICAS. NBR NM 45: Agregados Determinação da massa unitária e do volume de vazios. Rio de Janeiro, 2006.

ASSOCIAÇÃO BRASILEIRA DE NORMAS TÉCNICAS. NBR NM 52: Agregado miúdo Determinação da massa específica e massa específica aparente. Rio de Janeiro, 2009.

ASSOCIAÇÃO BRASILEIRA DE NORMAS TÉCNICAS. NBR NM 248: Agregados Determinação da composição granulométrica. Rio de Janeiro, 2003.

ASSOCIAÇÃO BRASILEIRA DE NORMAS TÉCNICAS. NBR 7211: Agregados para concreto - Especificação. Rio de Janeiro, 2005.

ASSOCIAÇÃO BRASILEIRA DE NORMAS TÉCNICAS. NBR 7215: Cimento Portand Determinação da Resistência à Compressão. Rio de Janeiro, 1996.

ASSOCIAÇÃO BRASILEIRA DE NORMAS TÉCNICAS. NBR 13276: Argamassa para assentamento e revestimento de paredes e tetos - Preparo da mistura e determinação do índice de consistência. Rio de Janeiro, 2002.

ASSOCIAÇÃO BRASILEIRA DE NORMAS TÉCNICAS. NBR 13278: Argamassa para assentamento e revestimento de paredes e tetos - Determinação da densidade de massa e do teor de ar incorporado. Rio de Janeiro, 2005.

ASSOCIAÇÃO BRASILEIRA DE NORMAS TÉCNICAS. NBR 13279: Argamassa para assentamento e revestimento de paredes e tetos - Determinação da resistência à tração na flexão e à compressão. Rio de Janeiro, 2005.

ASSOCIAÇÃO BRASILEIRA DE NORMAS TÉCNICAS. NBR 13281: Argamassa para assentamento e revestimento de paredes e tetos - requisitos. Rio de Janeiro, 2005. 
BLOG PRA CONSTRUIR. O que são argamassas? Disponível em:

$<$ http://blogpraconstruir.com.br/etapas-da-construcao/argamassas/>. Acesso em: 12 mar. 2019.

CIVILIZAÇÃO ENGENHARIA. Argamassa pronta na Construção Civil. Disponível em: $<$ https://civilizacaoengenheira.wordpress.com/2015/08/24/argamassa-pronta-naconstrucao-civil/>. Acesso em: 12 mar. 2019.

COIMBRA, M. A.; MORELLI, M. R. Desenvolvimento de argamassas microporosas para a construção civil. DEMa-UFSCar, São Carlos, 1999. Disponível em: $<$ http://www.scielo.br/scielo.php?script=sci_arttext\&pid=S036669131999000600008\&lang=pt>. Acesso em: 19 mar. 2019.

COSTA, Ivandro da. Estudo comparativo entre as argamassas de revestimento externo: preparada em obra, industrializada fornecida em sacos, e estabilizada dosada em central. 2016. 84 f. Trabalho de Conclusão de Curso (Graduação) Curso de Engenharia Civil. UNIVATES, Universidade do Vale do Taquari.

DAFICO, Dario de Araújo; FERRO, Kátia Maria de Souza; CAVALCANTE, Márcia Cardoso de Oliveira. Análise De Desempenho De Aditivos Impermeabilizantes Para Argamassas. In: CONFERÊNCIA LATINO-AMERICANA DE CONSTRUÇÃO SUSTENTÁVEL X ENCONTRO NACIONAL DE TECNOLOGIA DO AMBIENTE CONSTRUÍDO, 4., São Paulo. Anais eletrônicos... São Paulo: claCS'04 x ENTAC'04, 2004.

SANTIAGO, Cybéle Celestino. Argamassas tradicionais de cal. Salvador: EDUFBA, 2007.

SCHWARTZ, Mônica M.; CASSOL, Gabriela. Estudo comparativo entre o concreto com adição de nanosílica e o concreto com adição de sílica ativa em suspensão. Disponível em: https://periodicos.uniarp.edu.br/index.php/ignis/article/view/1813/929 . Acesso em: 15 nov. 2019.

VEDACIT. VEDACIT. Disponível em: < http://vedacit.com.br/produtos/vedacit>. Acesso em: 21 abr. 2019.

WERNER, Jean C..Elementos cerâmicos e argamassas de assentamento- uma avaliação das condições de utilização em obras de Condor e Panambi. 2004. 62 f. Trabalho de Conclusão de Curso (graduação em engenharia civil) - Departamento de tecnologia.UNIJUÍ, Universidade Regional do Noroeste do Estado do Rio 
Grande do Sul, ljuí.

Ignis / Caçador | v.8 | n.2 | p. 54-79 | maio/ago. 2019 